\title{
Polypropylene-based graft copolymers via CuAAC click chemistry
}

\author{
G. Acik ${ }^{1,2}$, E. Sey ${ }^{3}$, M. A. Tasdelen ${ }^{1 *}$ \\ ${ }^{1}$ Department of Polymer Engineering, Faculty of Engineering, Yalova University, TR-77100 Yalova, Turkey \\ ${ }^{2}$ Department of Chemistry, Faculty of Sciences and Letters, Piri Reis University, Tuzla, 34940 Istanbul, Turkey \\ ${ }^{3}$ Department of Chemistry, Science Faculty, Trakya University, Edirne, Turkey
}

Received 12 October 2017; accepted in revised form 13 December 2017

\begin{abstract}
Graft copolymers from commercial chlorinated polypropylene ( $\mathrm{PP}-\mathrm{Cl}$ ) possessing either poly(ethylene glycol) (PEG) or poly( $\varepsilon$-caprolactone) (PCL) grafts are synthesized by copper (I)-catalyzed azide-alkyne cycloaddition 'click' reaction (CuAAC). For this purpose, azido-functional polypropylene is prepared by nucleophilic substitution of chlorine groups of PP-Cl with azidotrimethylsilane-tetrabutylammonium fluoride. Whereas, the clickable alkyne end-functional PEG and PCL are independently synthesized by esterification reaction of poly(ethylene glycol) methyl ether with 4-pentyonic acid at room temperature and ring-opening polymerization of $\varepsilon$-caprolactone using stannous octoate as catalyst and propargyl alcohol as initiator. Finally, the corresponding graft copolymers, PP-g-PEG and PP-g-PCL, with different surface properties were successfully synthesized by CuAAC 'click' reaction under mild condition. Spectral, chromatographic and thermal analyses at various stages prove the formation of desired polypropylene-based graft copolymers with well-defined properties. Furthermore, the water contact angle values of PP-Cl, PP- $g$-PEG and PP-g-PCL are found as $90 \pm 1^{\circ}, 78 \pm 1.8^{\circ}$ and $83 \pm 2.1^{\circ}$, respectively.
\end{abstract}

Keywords: polymer synthesis, chlorinated polypropylene, copper (I)-catalyzed azide-alkyne cycloaddition, graft copolymers, water contact angle

\section{Introduction}

Polyolefins comprising polypropylene, polyethylene, polyisobutylene, poly-1-butene, ethylene propylene diene rubber and ethylene propylene elastomer are known as the most widely used polymers in particular applications such as automotive, bottles, containers, hoses, garbage and bread bags etc. $[1,2]$. The low cost, good mechanical and physical properties, both superior recyclability and processability are the key factors for selecting the polyolefins compared to other polymers in these applications. Since all polyolefins are aliphatic hydrocarbons consisting of only hydrogen and carbon atoms, they show poor wettability and adhesion characteristics. To overcome these limitations, the modification of polyolefins as a serious research area in polymer science has come into prominence [3, 4]. Due to the absence of polar groups, semi-crystalline morphology, resistance to polar or ionic chemicals and limited chemical substitution, oxidation and free radical reactions, these modifications are quite challenging and usually are difficult to maintain [5]. There are two main modification methods in the literature: (i) direct copolymerization of either $\alpha$-olefin $[6,7]$ or polar monomers [8,9] and (ii) chemical modification of preformed polymers $[10,11]$. For example, antibacterial [12], antifouling [13] and hydrogen storage [14] properties of polypropylene were enhanced via surface-initiated atom transfer radical polymerization [15]. Chlorine atoms on the polymer chains both develop polarity and allow reactive sites for a series of monomer such as acrylates, methacrylates and styrenes [16-19]. Polymers 
containing chlorine atoms, such as chlorinated poly (vinyl chloride) (CPVC), poly(vinyl chloride) (PVC), chlorinated polyethylene and polypropylene exhibit high fire and cold resistance as well as plasticity. These beneficial properties make them good choices for a number of industrial applications [20-25]. Among them, chlorinated polypropylene (PP-Cl) has been found many applications including paints, printing ink binders, overprint varnishes, sealing compounds and waterproof agents, due to its superior abrasive, ageing chemical resisting properties, and heat and light stability.

After successful discovery of click chemistry concept by Sharpless and Meldal, it is easy to perform polymer modification with high yield under mild conditions, such as rapid, stereospecific, orthogonal and no by-product coherent with the green chemistry [26]. Today, a series of reactions including Huisgen type $\mathrm{Cu}(\mathrm{I})$ catalyzed cycloaddition (CuAAC) [27, 28], thiol-ene [29-31] and Diels-Alder [32] are recognized as well-known click chemistry reactions [33]. Modification of polymers with CuAAC click reaction is very general, robust and particularly simple compared to other click chemistry reactions [34-37]. During the recent years, these reactions have been extensively applied for the modification of commercially available polymers such as PVC [38-41], polyethylene [42] and polypropylene [43, 44].

In the frame of our continuous interest in developing novel polymeric materials from commercially available polymers, here, the modification of chlorinated polypropylene with poly(ethylene glycol) and poly( $\varepsilon$ caprolactone) was achieved by CuAAC click chemistry under mild conditions. In this case, clickable azide functionality was introduced to commercial chlorinated polypropylene by using azidotrimethylsilane-tetrabutylammonium fluoride. In addition, the alkyne-functionalized poly(ethylene glycol) and poly ( $\varepsilon$-caprolactone) were independently produced by esterification of poly(ethylene glycol) methyl ether by using 4-pentynoic acid and classical ring opening polymerization of $\varepsilon$-caprolactone initiated by propargyl alcohol and catalyzed by tin(II) 2-ethylhexanoate. The subsequent $\mathrm{CuAAC}$ click reactions of these polymers enabled to attain graft copolymers based on polypropylene. The successful formation of graft copolymers were confirmed by spectral, chromatographic and thermal analyses. Furthermore, the surface properties of obtained graft copolymers were also investigated by water contact angle measurement.

\section{Experimental part}

\subsection{Materials}

Chlorinated polypropylene $\left(\mathrm{PP}-\mathrm{Cl}, \quad M_{\mathrm{n}, \mathrm{GPC}}=\right.$ $50000 \mathrm{~g} / \mathrm{mol}$ determined by GPC measurement), chlorine mass fraction: $29-32 \%[\mathrm{~m} / \mathrm{m}]$ was purchased from Mark Zhang Shanghai Sunking Industry Incorporation (China). Azidotrimethylsilane (TMS-N $\mathrm{N}_{3}$ is flammable chemical, $95 \%$ ), solution of tetrabutylammonium fluoride (TBAF, 1.0 M in THF), poly(ethylene glycol) methyl ether (mPEG, $M_{\mathrm{n}}=5000 \mathrm{~g} / \mathrm{mol}$ ), 4-dimethylaminopyridine (DMAP, 99\%), N,N'-dicyclohexylcarbodiimide (DCC, 99\%), propargyl alcohol (99\%), $\varepsilon$-caprolactone ( $\varepsilon$-CL, 97\%) and tin(II) 2-ethylhexanoate $\left(\mathrm{Sn}(\mathrm{Oct})_{2}, 92.5-100.0 \%\right)$, copper(I) chloride $(\mathrm{CuCl}, 99.99 \%)$ and $N, N, N^{\prime}, N^{\prime \prime}, N^{\prime \prime}$-pentamethyldiethylenetriamine (PMDETA, 99\%) were purchased from Sigma Aldrich (Steinheim, Germany) and used as received. 4-pentynoic acid (98\%, Alfa Aesar, Haverhill, ABD) used as received. Tetrahydrofuran (anhydrous, $\geq 99.9 \%$, inhibitor-free, Sigma Aldrich, Steinheim, Germany), methanol (for HPLC, $\geq 99.9 \%$, Sigma Aldrich, Steinheim, Germany), toluene (anhydrous, 99.8\%, Sigma Aldrich, Steinheim, Germany), hexane (anhydrous, 95\%, Sigma Aldrich, Steinheim, Germany), dichloromethane (anhydrous, $\geq 99.8 \%$, Sigma Aldrich, Steinheim, Germany) and diethyl ether (for analysis EMSURE ${ }^{\circledR}$, Sigma Aldrich, Steinheim, Germany) were used without distillation. Glass cover slides sized 76 to $26 \mathrm{~mm}$ were purchased from ISOLAB (Istanbul, Turkey) and used for dipcoating.

\subsection{Instrumentation}

Fourier transform infrared (FT-IR) analyses were performed by Spectrum Two Spectrometer (PerkinElmer, Waltham, USA) equipped with a diamond ATR device for verify specific groups of intermediates and final products. ${ }^{1} \mathrm{H}-\mathrm{NMR}$ measurements were recorded by Varian $400 \mathrm{MHz}$ NMR (Palo Alto, California, USA) spectrometer in chloroform-d with tetramethylsilane.

Gel permeation chromatography (GPC) analyses were determined by Viscotek GPCmax consisting of a refractive index (RI) detector (VE 3580, Viscotek) and a pump module (GPC max, Viscotek, Houston, TX) with flow rate $1 \mathrm{~mL} / \mathrm{min}$. In analyses injections autosampler system and $50 \mu \mathrm{L}$ injection volume were used. The calibration of RI detector was done by narrow molecular weight polystyrene standards. Two columns (LT5000L, Mixed, Medium Organic $300 \times 8 \mathrm{~mm}$ and 
LT3000L, Mixed, Ultra-Low Organic $300 \times 8 \mathrm{~mm}$ ) with a guard column (TGuard, Organic Guard Column $10 \times 4.6 \mathrm{~mm}$ ) were used for the tetrahydrofuran eluent at $35^{\circ} \mathrm{C}$. Viscotek OmniSEC Omni-01 software were used to analyze the data. Differential scanning calorimetry (DSC) measurements were conducted to determine both melting temperatures and glass transition temperatures using Perkin-Elmer brand device (Waltham, USA) with diamond equipment with a heating rate of $10^{\circ} \mathrm{C} / \mathrm{min}$ under nitrogen flow $(10 \mathrm{~mL} / \mathrm{min})$. Water contact angle (WCA) measurements was performed by KSV Attension Theta Optical Tensiometer (CAM-200, Vastra Frolunda, Sweden) using water for chromatography (LC-MS Grade) at room temperature.

\subsection{General procedure for azide-functional polypropylene ( $\left.\mathrm{PP}-\mathrm{N}_{\mathbf{3}}\right)$}

According to a typical azidation procedure [45]; PP$\mathrm{Cl}\left(1.0 \mathrm{~g}, 2 \cdot 10^{-2} \mathrm{mmol}\right)$ was dissolved in THF $(5 \mathrm{~mL})$ and added in a $20 \mathrm{~mL}$ one necked flat bottomed flask, equipped with magnetic stirrer bar. Then, the TMS-N 3 $(0.2 \mathrm{~mL}, 1.7 \mathrm{mmol})$ and TBAF $(0.5 \mathrm{~mL}, 1.5 \mathrm{mmol})$ were added by drop-wise, respectively. Subsequently, purged with nitrogen gas for $10 \mathrm{~min}$, formulation was left under vigorous stirring for $24 \mathrm{~h}$ heated up to $60^{\circ} \mathrm{C}$ in oil bath. After the given time, the obtained PP- $\mathrm{N}_{3}$ solution was precipitated with nearly 10 times excess methanol. This solution was filtered and dried under vacuum to remove residual solvent. (Yield $=$ $90 \%, M_{\mathrm{n}, \mathrm{GPC}}=50000 \mathrm{~g} \cdot \mathrm{mol}^{-1}$ )

\subsection{Synthesis of alkyne end-functionalized poly(\&-caprolactone) (PCL-alkyne)}

Synthesis procedure of alkyne end-functionalized poly( $\varepsilon$-caprolactone) was carried out according to previous literatures $[46,47]$. Briefly, monomer $\varepsilon$ caprolactone $(5 \mathrm{~mL}, 47 \mathrm{mmol})$, propargyl alcohol $(0.1 \mathrm{~mL}, 1.2 \mathrm{mmol})$ as an initiator and $\mathrm{Sn}(\mathrm{Oct})_{2}$ (three drops by using pasteur pipette) as a catalyst in $5 \mathrm{~mL}$ toluene were added in a $20 \mathrm{~mL}$ one necked flat bottomed flask that flamed previously and equipped with magnetic stirrer bar. The polymerization was conducted at $110^{\circ} \mathrm{C}$ for $18 \mathrm{~h}$. After the polymerization, the mixture was precipitated with nearly 10 times excess hexane. This solution was filtered and dried under vacuum. (Yield $=61 \%, M_{\text {n,theo }}=2800 \mathrm{~g} \cdot \mathrm{mol}^{-1}$, $\left.M_{\mathrm{n}, \mathrm{GPC}}=3100 \mathrm{~g} \cdot \mathrm{mol}^{-1}, M_{\mathrm{n}, \mathrm{NMR}}=2700 \mathrm{~g} \cdot \mathrm{mol}^{-1}\right)$.

\subsection{Synthesis of alkyne-end functionalized poly(ethylene glycol) methyl ether (PEG-alkyne)}

Synthesis procedure of alkyne functionalized poly(ethylene glycol) methyl ether was performed according to previous literatures [48-50]. Briefly, the mPEG (3 g, $0.6 \mathrm{mmol}$ ) solution in $25 \mathrm{~mL} \mathrm{CH}_{2} \mathrm{Cl}_{2}$, 4-pentyonic acid $(0.22 \mathrm{~g}, 2.25 \mathrm{mmol})$, DMAP $(0.09 \mathrm{~g}$, $0.75 \mathrm{mmol})$ and DCC (0.45 g, $2.25 \mathrm{mmol})$ solution in $10 \mathrm{~mL} \mathrm{CH}_{2} \mathrm{Cl}_{2}$ were added into a $250 \mathrm{~mL}$ one necked flat bottomed flask, equipped with magnetic stirrer bar. Then the mixture was left under vigorous stirring for $24 \mathrm{~h}$. at room temperature. And then, the PEGalkyne solution was purified by column chromatography. The solution was precipitated with nearly 10 times excess diethyl ether. Then, the precipitate was filtered and dried under vacuum. (Yield $=48 \%$, $M_{\mathrm{n}, \text { theo }}=5100 \mathrm{~g} \cdot \mathrm{mol}^{-1}, \quad M_{\mathrm{n}, \mathrm{GPC}}=4200 \mathrm{~g} \cdot \mathrm{mol}^{-1}$, $\left.M_{\mathrm{n}, \mathrm{NMR}}=5500 \mathrm{~g} \cdot \mathrm{mol}^{-1}\right)$.

\subsection{Synthesis of polypropylene-based graft copolymers via $\mathrm{CuAAC}$ click chemistry (PP-g-PCL and PP-g-PEG)}

In a $25 \mathrm{~mL}$ flask pre-heated to $50^{\circ} \mathrm{C}$ with magnetic stirrer, $\mathrm{PP}-\mathrm{N}_{3}\left(0.5 \mathrm{~g}, 1 \cdot 10^{-2} \mathrm{mmol}\right)$, PCL-alkyne $\left(0.48 \mathrm{~g}, 1 \cdot 10^{-1} \mathrm{mmol}\right)$ or PEG-alkyne $(0.5 \mathrm{~g}$, $\left.1 \cdot 10^{-1} \mathrm{mmol}\right)$, ligand PMDETA $\left(6.3 \mu \mathrm{L}, 3 \cdot 10^{-2} \mathrm{mmol}\right)$ and catalyst $\mathrm{CuCl}\left(3 \mathrm{mg}, 3 \cdot 10^{-2} \mathrm{mmol}\right)$ were added and dissolved in THF $(15 \mathrm{~mL})$. Before the reaction mixture was left to refill with nitrogen for $10 \mathrm{~min}$ degassed by vacuum and stirred for $24 \mathrm{~h}$. After the given reaction time final solution was diluted with THF and passed from neutral alumina to remove metal salts. This eluent was concentrated by evaporation and precipitated with cold methanol before dried under vacuum about overnight at room temperature.

\subsection{Water contact angle measurement}

A homemade mechanical dip coater was used to coating to glass substrate with solution of precursor and obtained polypropylene-based graft copolymers. Before the dip coating glass slides which are used as substrate in coating procedure were cleaned in chromic acid and then rinsed with de-ionized water two times. $150 \mathrm{mg} / \mathrm{mL}$ concentration of PP-Cl, PP-gPCL and PP- $g$-PEG solutions were prepared in THF and glass cover slides dipped into them by using 
homemade mechanical dip coater at room temperature (withdraw rate: $100 \mathrm{~mm} / \mathrm{min}$, waiting duration: $30 \mathrm{~min}$ ) to obtain uniform surfaces. After given time coated glass slides were held under vacuum to remove residual solvents for $24 \mathrm{~h}$ before the WCA measurements.

\section{Results and discussion}

Graft copolymers with different topologies prepared since many decades for numerous applications are the general type of segmented copolymers that branches of different composition randomly linked to a linear polymer backbone. Due to their ultimate mechanical, thermal and solution properties compared with linear polymers, they have been utilized as surfactant, nanocarrier, emulsifier, biosensor, compatibilizer, resistance material and thermoplastic elastomer [1]. Generally, there are three type synthesis methods for graft copolymers including (i) grafting through or macromonomer method, (ii) grafting from and (iii) grafting onto methods [51-53]. After the discovery of click chemistry reactions, the use grafting onto method is more applicable than others. Thanks to click chemistry reactions, a series of difficulties such as poor selectivity, low grafting efficiency and tolerance to a variety of solvents and functional groups can be simply eliminated in the synthesis of graft copolymers. In the present paper, polypropylene based graft copolymers including PP- $g$-PCL and PP- $g$-PEG from chlorinated polypropylene were successfully prepared via grafting onto method using CuAAC click chemistry (Figure 1.)

The structures of obtained PP- $g$-PCL, PP- $g$-PEG and intermediates were firstly confirmed by both FT-IR and ${ }^{1} \mathrm{H}$ - NMR spectroscopies. In Figures 2 and 3, it can be seen that characteristic C-Cl band of $\mathrm{PP}-\mathrm{Cl}$ at around $730 \mathrm{~cm}^{-1}$ were disappeared, while a sharp peak corresponding to $-\mathrm{N}_{3}$ group at around $2095 \mathrm{~cm}^{-1}$ was appeared after the azidation reaction. Moreover, the stretching alkyene peaks of the PCL-alkyne or PEG-alkyne appeared in both spectrums at around

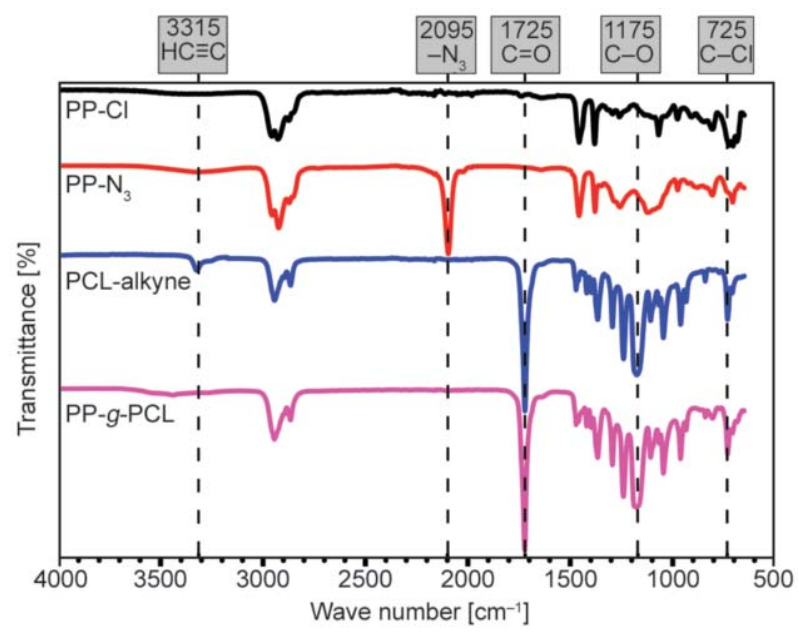

Figure 2. FT-IR spectra of PP-Cl, PP-N 3 , PCL-alkyne and PP-g-PCL.

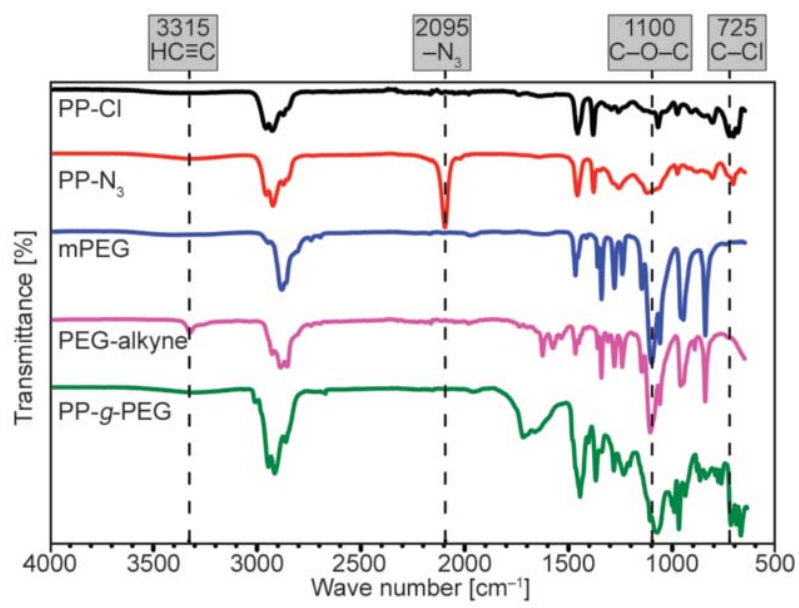

Figure 3. FT-IR spectra of PP-Cl, PP-N 3 , mPEG, PEG-alkyne and PP- $g$-PEG.

$3315 \mathrm{~cm}^{-1}$ after ring opening polymerization and esterification reaction, respectively. According to FTIR analysis, the complete disappearances of azide and alkyne peaks as well as appearance of $>\mathrm{C}=\mathrm{O}$ band at around $1725 \mathrm{~cm}^{-1}$ for PP- $g$-PCL, etheric $\mathrm{C}-\mathrm{O}-\mathrm{C}$ band at around $1100 \mathrm{~cm}^{-1}$ and $-\mathrm{C}-\mathrm{O}$ band at around $1175 \mathrm{~cm}^{-1}$ for PP- $g$-PEG indicated the successive formation of desired polypropylene based graft copolymers.

To confirm the chemical structures of polypropylene-based copolymers and intermediates, ${ }^{1} \mathrm{H}-\mathrm{NMR}$

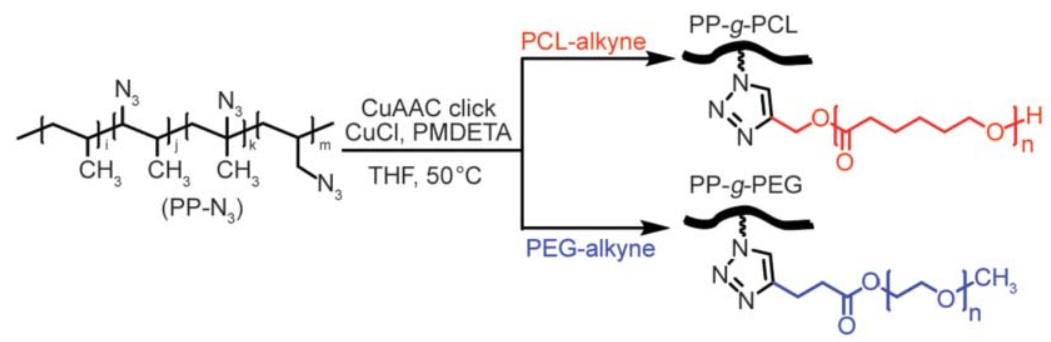

Figure 1. Polypropylene-based graft copolymers from PP-Cl via CuAAC click chemistry. 
studies were conducted. As depicted in Figures 4 and 5 , there were mainly two types of protons belonging to $\mathrm{PP}-\mathrm{Cl}$ samples; the protons attached to $-\mathrm{Cl}$ bounded carbons $\left(-\mathrm{CH}_{2}-\mathrm{Cl}\right.$ and $\left.-\mathrm{CH}-\mathrm{Cl}\right)$ and aliphatic protons $\left(-\mathrm{CH}_{2}-\right.$ and $\left.-\mathrm{CH}-\right)$ of the main chain. The aliphatic protons (1-3 and 5-10) were appeared resonance between 1.71 and $2.81 \mathrm{ppm}$, while the other protons (4 and 11) were seen at 3.55 and $3.68 \mathrm{ppm}$, respectively [20]. After the azidation process, new peaks ( $\mathrm{a}$ and $\mathrm{b}$ ) belonging to protons attached to $-\mathrm{N}_{3}$ bounded carbon atoms were appeared at 2.24 and $3.22 \mathrm{ppm}$, whereas the remaining $-\mathrm{Cl}$ bounded carbon protons (4 and 11) were still observed in the PP-N $\mathrm{N}_{3}$ sample. The ${ }^{1} \mathrm{H}-\mathrm{NMR}$ spectra of PCL-alkyne and corresponding PP-g-PCL samples were also presented in Figure 4. As can be seen that the disappearances of characteristic alkyne and azide peaks; methine (c) $4.7 \mathrm{ppm}$ and methylene (d) protons at $2.5 \mathrm{ppm}$ of PCL-alkyne and methine (a) and methylene (b) as well as the appearance of triazole proton (c) at $8.12 \mathrm{ppm}$ were great evidences for the successful formation of clicked product PP-g-PCL [54]. Also in Figure 5, the structure of another PP$g$-PEG copolymer was also analyzed by ${ }^{1} \mathrm{H}-\mathrm{NMR}$ spectroscopy and the similar results were observed [45, 55-58]. Furthermore, the composition of graft copolymers were also calculated from integration ratios of specific resonances belonging to each segments by using following formulas Equations (1) and (2) for PP- $g$-PCL and PP- $g$-PEG and the result summarized in Table 1. The molar content of the polypropylene in the PP-g-PCL was found $88 \%$, while it was $72 \%$ for PP-g-PEG. This difference could be explained by the higher chain length of PEG-alkyne, which partially increase the PEG content as well as decrease the PP content in the PP-gPEG. All of these results confirmed the chemical structures of PP- $g$-PCL and PP- $g$-PEG.

$$
\mathrm{PP}[\%]=\left[\frac{\left(\frac{3+6+7+9}{10}\right)}{\left(\frac{\mathrm{o}}{2}\right)+\left(\frac{3+6+7+9}{10}\right)}\right] \cdot 100
$$

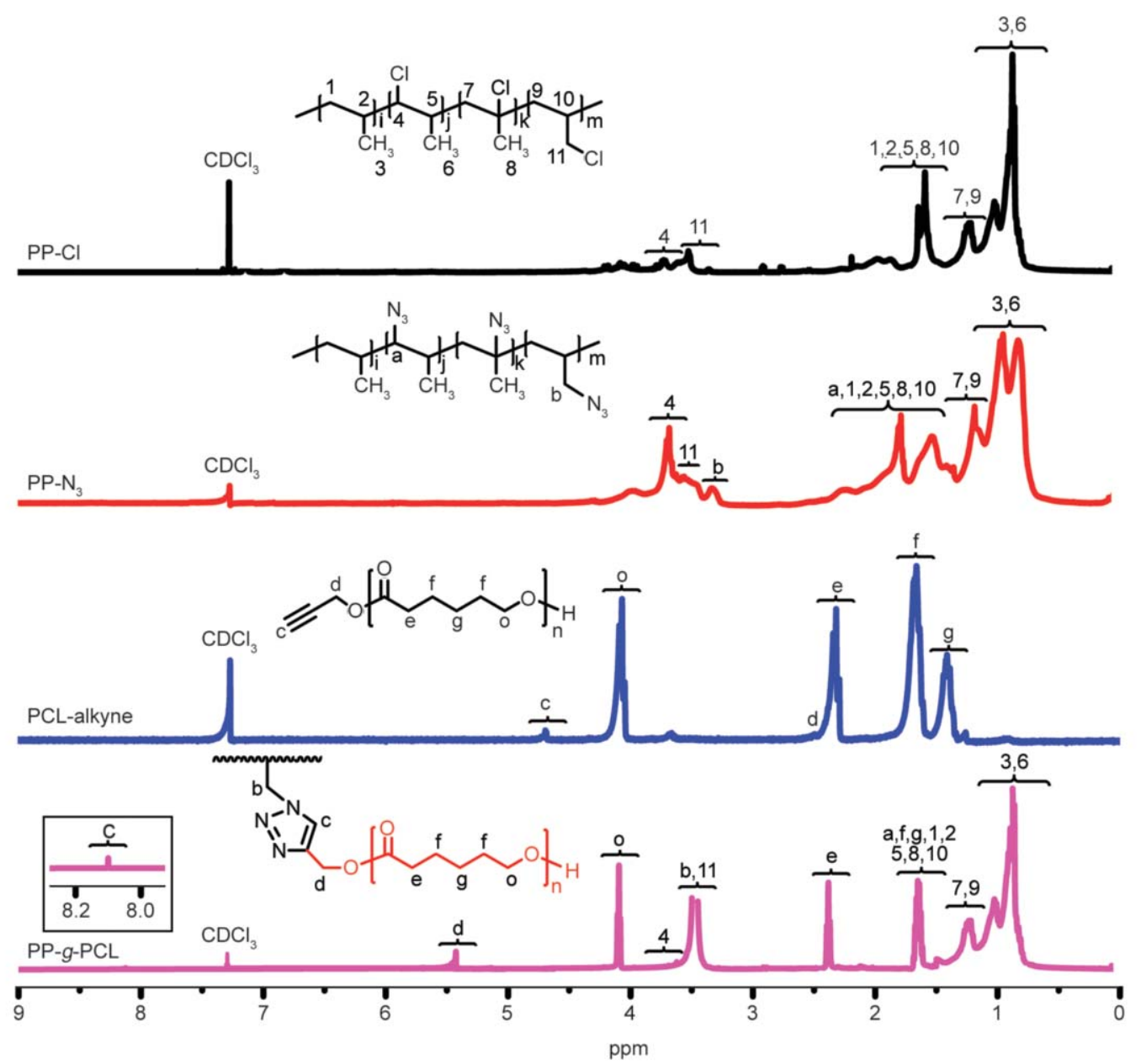

Figure 4. ${ }^{1} \mathrm{H}-\mathrm{NMR}$ spectra of PP-Cl, PP-N 3 , PCL-alkyne and PP-g-PCL. 


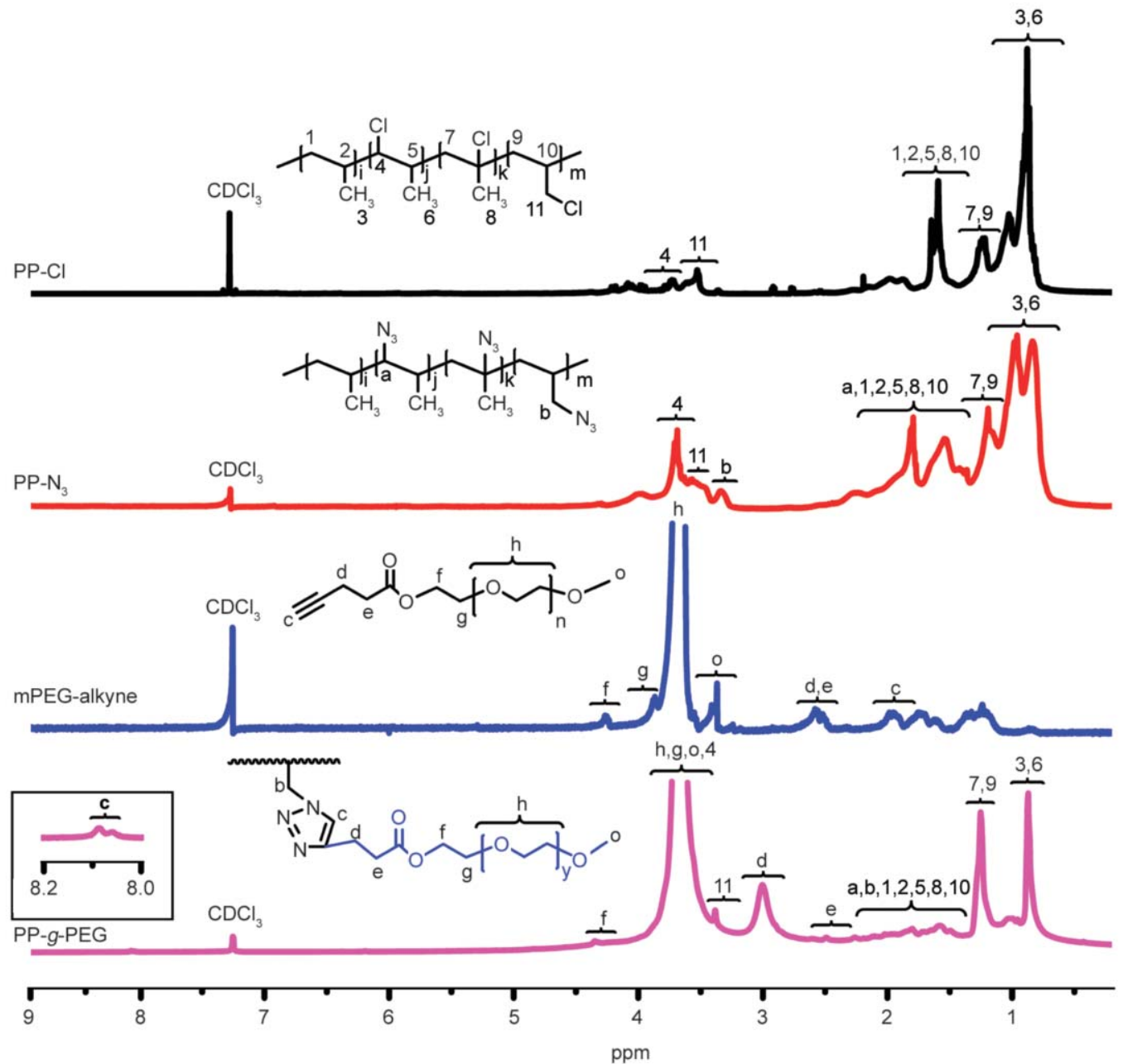

Figure 5. ${ }^{1} \mathrm{H}-\mathrm{NMR}$ spectra of PP-Cl, PP-N 3 , PEG-alkyne and PP-g-PEG.

$$
\mathrm{PP}[\%]=\left[\frac{\left(\frac{3+6+7+9}{10}\right)}{\frac{(4+11+\mathrm{b}+\mathrm{h}+\mathrm{g}+\mathrm{o})-\left(3 \cdot \frac{3+6+7+9}{10}\right)}{4}+\left(\frac{3+6+7+9}{10}\right)}\right] \cdot 100
$$

Table 1. The molecular weight and thermal properties of PP- $g$-PCL and PP-g-PEG, and their precursors.

\begin{tabular}{|l|c|c|c|c|c|c|}
\hline \multicolumn{1}{|c|}{ Polymer } & $\begin{array}{c}\text { Conv. }^{\mathbf{a}} \\
{[\mathbf{\%}]}\end{array}$ & $\begin{array}{c}\boldsymbol{M}_{\mathbf{n}, \mathbf{G P C}^{\mathbf{b}}} \\
{\left[\mathbf{g} \cdot \mathbf{m o l}^{-\mathbf{1}}\right]}\end{array}$ & $\boldsymbol{\#}^{\mathbf{b}}$ & $\begin{array}{c}\mathbf{C o m p .}^{\mathbf{c}} \\
{[\mathbf{P P} \mathbf{0}]}\end{array}$ & $\begin{array}{c}\boldsymbol{T}_{\mathbf{g}}^{\mathbf{d}} \\
{\left[{ }^{\circ} \mathbf{C}\right]}\end{array}$ & $\begin{array}{c}\boldsymbol{T}_{\mathbf{m}}{ }^{\mathbf{d}} \\
{\left[{ }^{\circ} \mathbf{C}\right]}\end{array}$ \\
\hline PP-Cl & - & 50000 & 3.21 & 100 & 39 & not determined. \\
\hline PP-N ${ }_{3}$ & - & 52000 & 3.23 & 100 & 36 & not determined. \\
\hline PCL-alkyne & 61 & 3100 & 1.85 & - & not determined. & 58 \\
\hline PEG-alkyne & 48 & 4200 & 1.21 & - & not determined. & 55 \\
\hline PP-g-PCL & 45 & 88000 & 1.98 & 88 & not determined. & 54 \\
\hline PP-g-PEG & 53 & 38000 & 2.29 & 72 & not determined. & 49 \\
\hline
\end{tabular}

${ }^{\mathrm{a}}$ Calculated gravimetrically; ${ }^{\mathrm{b}}$ The molecular weight $\left(M_{\mathrm{n}, \mathrm{GPC}}\right)$ and distribution $(\nexists)$ were determined by gel permeation chromatography; ${ }^{\mathrm{c}}$ The compositions were calculated by ${ }^{1} \mathrm{H}-\mathrm{NMR}$ using Equations (1) and (2); ${ }^{\mathrm{d}}$ Determined by differential scanning calorimetry.

The molecular weights and distributions of obtained graft copolymers and intermediates polymers were investigated by GPC analysis. According to Figures 6, both graft copolymer and precursor samples displayed unimodal peaks without a shoulder. Interestingly, after the click reactions, the GPC chromatogram of PP-g-PCL sample shifted to higher molecular weight (from 50000 to $88000 \mathrm{~g} \cdot \mathrm{mol}^{-1}$ ), but the other chromatogram belonging to PP-g-PEG sample were moved to lower molecular weight (from 50000 to 

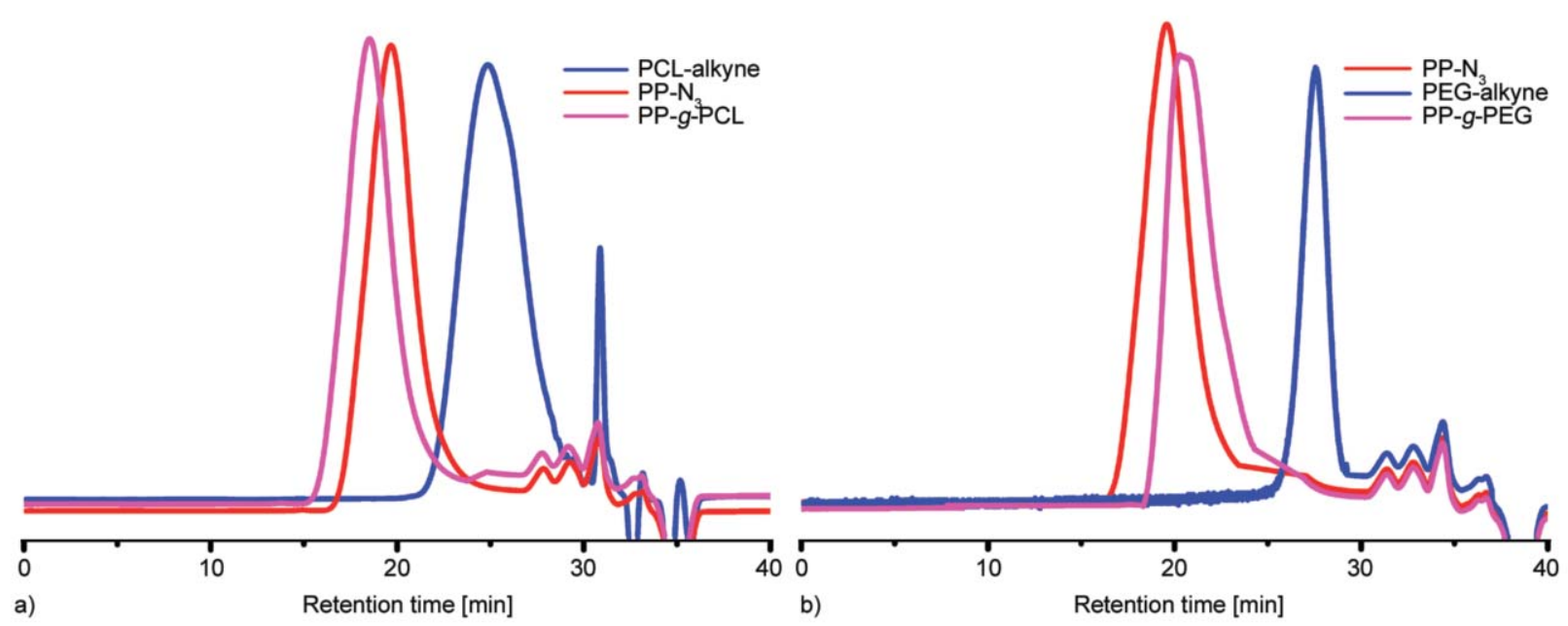

Figure 6. GPC traces of precursor PCL-alkyne, PP-N 3 and PP-g-PCL (a), PP-N 3 , PCL-alkyne and PP-g-PEG (b).

$\left.38000 \mathrm{~g} \cdot \mathrm{mol}^{-1}\right)$. This decrease might be due to the hydrophilic behavior of PEG segments, which strongly interacted with the stationary phase [59]. Therefore, the molecular weight of PP- $g$-PEG sample was decreased with respect to linear $\mathrm{PP}-\mathrm{N}_{3}$. The similar behaviors were also reported by previously published studies [60-62]. For example, the molecular weight was decreased to $21520 \mathrm{~g} \cdot \mathrm{mol}^{-1}$ in the synthesis of well-defined amphiphilic polysulfones- $g$ poly(ethylene glycol) starting from $\mathrm{PSU}_{3}$ $\left(25600 \mathrm{~g} \cdot \mathrm{mol}^{-1}\right)$ and PEG $\left(550 \mathrm{~g} \cdot \mathrm{mol}^{-1}\right)$ precursors [63]. It was also noted that polydispersities of the obtained PP- $g$-PCL $(~ D=1.98)$ and PP- $g$-PEG $(\nexists=2.29)$ were narrower than the $\mathrm{PP}-\mathrm{Cl}$ sample $(\nexists=3.21)$ and these data were acceptable for graft copolymers. (Table 1). Notably, the combination of well-defined side chains with commercial PP-Cl could decrease the polydispersities of obtained graft copolymers [63]. These results together with ${ }^{1} \mathrm{H}-\mathrm{NMR}$ spectroscopy confirmed the successful synthesis of graft copolymers from commercially available precursors. The thermal properties of the graft copolymers and precursor backbone were further analyzed by differential scanning calorimeter (DSC). The neat PCL and PEG segments exhibited semi-crystalline characteristics having a glass transition $\left(-60\right.$ and $\left.-55^{\circ} \mathrm{C}\right)$ and a melting $\left(58\right.$ and $\left.55^{\circ} \mathrm{C}\right)$ temperatures. As shown in Figure 7, while the $\mathrm{PP}-\mathrm{Cl}$ and $\mathrm{PP}-\mathrm{N}_{3}$ displayed a glass transition temperature $\left(T_{\mathrm{g}}\right)$ at 39 and $36^{\circ} \mathrm{C}$ respectively, after CuAAC click reactions, this $T_{\mathrm{g}}$ was not detected in both PP- $g$-PCL and PP- $g$-PEG samples. This might be explained by overlapping of $T_{\mathrm{g}}$ with the melting peaks of PP-g-PCL and PP-g-PEG that were detected at 54 and $49^{\circ} \mathrm{C}$, respectively. On the other hand, the melting points of PCL and PEG

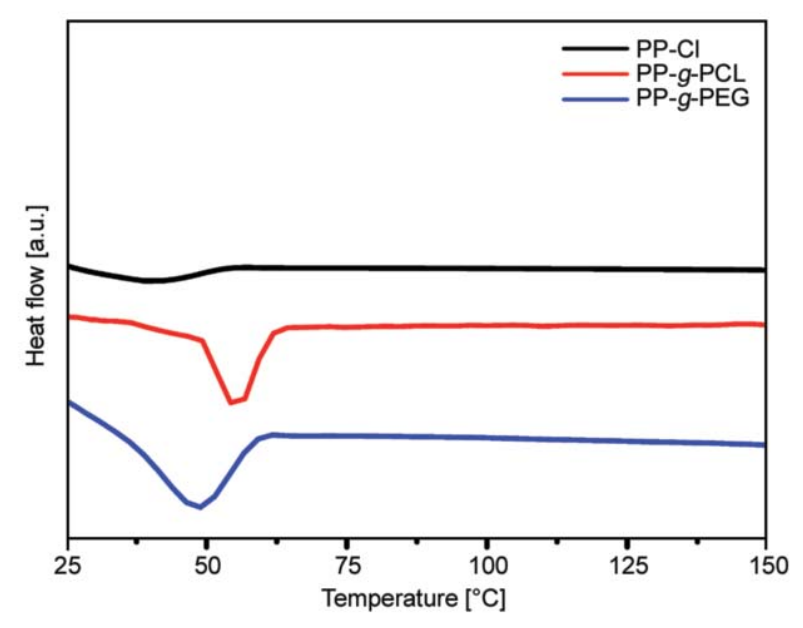

Figure 7. DSC thermograms of PP-Cl, PP-g-PCL and PP-gPEG samples.

segments were slightly shifted to lower temperatures. These change could be due to the segmental mobility, polarity and rigidity of backbone compared with the other segments $[64,65]$.

The surface properties of graft copolymers and initial PP-Cl sample were investigated by water contact angle (WCA) analysis at room temperature (Figure 8). While, the average WCA of a droplet of positioned on $\mathrm{PP}-\mathrm{Cl}$ coated substrate was in the range of $90 \pm 1^{\circ}$ that was in good agreement with the literature values [66-68].

By introduction of either hydrophilic PCL-alkyne (determined as $65 \pm 1.5^{\circ}$ ) [69-71], or PEG-alkyne (determined as $42 \pm 1.9^{\circ}$ ) units on the PP-Cl backbone, the WCA values of corresponding graft copolymers were decreased down to $83 \pm 2.1^{\circ}$ and $78 \pm 1.8^{\circ}$, respectively. The difference observed in the graft copolymers could be explained by the interaction of the polymer surface chains with the water. The apparently 


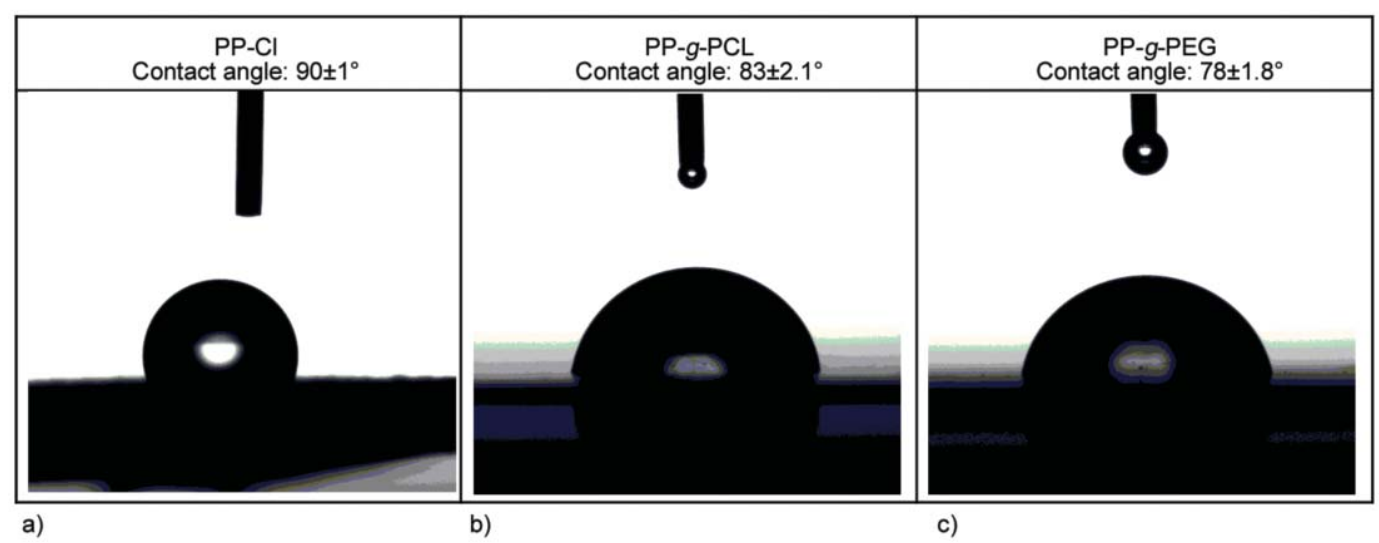

Figure 8. Shape of water drops on PP-Cl (a), PP-g-PCL (b) and PP-g-PEG (c) surfaces and their WCA measurements (Each measurement has been repeated ten times).

lower hydrophilicity of PP-g-PEG more likely resulted from a lower WCA value of PEG-alkyne [18, 72]. Overall, this simple route enabled to tailor the wettability of commercially available PP-Cl by inclusion of different type of polymers as pendant groups.

\section{Conclusions}

In summary, a simple and efficient method was described to obtain graft copolymers from commercially available sources normally required hard conditions due to the lack of polarity. Spectral FT-IR and ${ }^{1} \mathrm{H}-\mathrm{NMR}$ analysis proved that chemical structures of all intermediates and formation of polypropylenebased graft copolymers. Based on the GPC and DSC analyses, the molecular weight and thermal transition changes also confirmed the successful synthesis of graft copolymers. Furthermore, the desired properties such as wettability can be simply introduced onto polypropylene backbones that was clarified by WCA measurements. This facile route enables to expand the potential applications of commercially available chlorinated polypropylene such as particularly packaging, toys, building, automotive, transport and medical. Further studies in this line are now in progress.

\section{Acknowledgements}

One of the authors (G. A.) would like to acknowledge and thank Turkish Scientific and Technical Research Council (TUBITAK, Project No: 216Z060) by means of 1002-Short Term R\&D Funding Program for financial support. The authors would like to thank to Dr. Elif Özen Cansoy from Piri Reis University for WCA measurements.

\section{References}

[1] Chung T.: Synthesis of functional polyolefin copolymers with graft and block structures. Progress in Polymer Science, 27, 39-85 (2002).

https://doi.org/10.1016/S0079-6700(01)00038-7

[2] Gahleitner M.: Polyolefins for the 21st century. Express Polymer Letters, 5, 936 (2011).

https://doi.org/10.3144/expresspolymlett.2011.91

[3] Boaen N. K., Hillmyer M. A.: Post-polymerization functionalization of polyolefins. Chemical Society Reviews, 34, 267-275 (2005).

https://doi.org/10.1002/chin.200526251

[4] Jois Y. H. R., Harrison J. B.: Modification of polyolefins: An overview. Journal of Macromolecular Science Part C: Polymer Reviews, 36, 433-455 (1996). https://doi.org/10.1080/15321799608009646

[5] Chung T. M.: Functionalization of polyolefins. Academic Press, London (2002).

[6] Natta G., Pasquon I.: The kinetics of the stereospecific polymerization of $\alpha$-olefins. Advances in Catalysis, 11, 1-66 (1959). https://doi.org/10.1016/S0360-0564(08)60416-2

[7] Gromada J., Carpentier J-F., Mortreux A.: Group 3 metal catalysts for ethylene and $\alpha$-olefin polymerization. Coordination Chemistry Reviews, 248, 397-410 (2004). https://doi.org/10.1016/j.ccr.2004.02.002

[8] Boffa L. S., Novak B. M.: Copolymerization of polar monomers with olefins using transition-metal complexes. Chemical Reviews, 100, 1479-1494 (2000). https://doi.org/10.1021/cr990251u

[9] Dong J-Y., Hu Y.: Design and synthesis of structurally well-defined functional polyolefins via transition metalmediated olefin polymerization chemistry. Coordination Chemistry Reviews, 250, 47-65 (2006). https://doi.org/10.1016/j.ccr.2005.05.008

[10] Jagur-Grodzinski J.: Modification of polymers under heterogeneous conditions. Progress in Polymer Science, 17, 361-415 (1992). https://doi.org/10.1016/0079-6700(92)90020-Y 
[11] Ciftci M., Batat P., Demirel A. L., Xu G. J., Buchmeiser M., Yagci Y.: Visible light-induced grafting from polyolefins. Macromolecules, 46, 6395-6401 (2013).

https://doi.org/10.1021/ma401431h

[12] Huang J., Murata H., Koepsel R. R., Russell A. J., Matyjaszewski K.: Antibacterial polypropylene via surface-initiated atom transfer radical polymerization. Biomacromolecules, 8, 1396-1399 (2007).

https://doi.org/10.1021/bm061236j

[13] Coad B. R., Lu Y., Meagher L.: A substrate-independent method for surface grafting polymer layers by atom transfer radical polymerization: Reduction of protein adsorption. Acta Biomaterialia, 8, 608-618 (2012). https://doi.org/10.1016/j.actbio.2011.10.006

[14] Chen S., Liu J., Li Z., Wang H., Wang X., Xu Y.: Hydrogen storage properties of highly cross-linked polymers derived from chlorinated polypropylene and polyethylenimine. International Journal of Hydrogen Energy, 42, 23028-23034 (2017).

https://doi.org/10.1016/j.ijhydene.2017.07.101

[15] Król P., Chmielarz P.: Recent advances in ATRP methods in relation to the synthesis of copolymer coating materials. Progress in Organic Coatings, 77, 913-948 (2014). https://doi.org/10.1016/j.porgcoat.2014.01.027

[16] Gauthier M. A., Gibson M. I., Klok H-A.: Synthesis of functional polymers by post-polymerization modification. Angewandte Chemie International Edition, 48, 48-58 (2009).

https://doi.org/10.1002/anie.200801951

[17] Wang S-S., Zhao Z-Q., Wang N., Zhao J-R., Feng Y.: Structure and mechanism of functional isotactic polypropylene via in situ chlorination graft copolymerization. Polymer International, 60, 1068-1077 (2011). https://doi.org/10.1002/pi.3044

[18] Balcı M., Allı A., Hazer B., Güven O., Cavicchi K., Cakmak M.: Synthesis and characterization of novel comb-type amphiphilic graft copolymers containing polypropylene and polyethylene glycol. Polymer Bulletin, 64, 691-705 (2010). https://doi.org/10.1007/s00289-009-0211-3

[19] Kalaycı Ö. A., Cömert F. B., Hazer B., Atalay T., Cavicchi K. A., Cakmak M.: Synthesis, characterization, and antibacterial activity of metal nanoparticles embedded into amphiphilic comb-type graft copolymers. Polymer Bulletin, 65, 215-226 (2010).

https://doi.org/10.1007/s00289-009-0196-y

[20] Acik G., Tasdelen M. A.: Graft copolymers from commercial chlorinated polypropylene via $\mathrm{Cu}(0)$-mediated atom transfer radical polymerization. Polymer International, 65, 1458-1463 (2016).

https://doi.org/10.1002/pi.5202

[21] Jia P., Hu L., Feng G., Bo C., Zhang M., Zhou Y.: PVC materials without migration obtained by chemical modification of azide-functionalized pvc and triethyl citrate plasticizer. Materials Chemistry and Physics, 190, 2530 (2017).

https://doi.org/10.1016/j.matchemphys.2016.12.072
[22] Nayak V., Jyothi M., Balakrishna R. G., Padaki M., Deon S.: Novel modified poly vinyl chloride blend membranes for removal of heavy metals from mixed ion feed sample. Journal of Hazardous Materials, 331, 289299 (2017). https://doi.org/10.1016/j.jhazmat.2017.02.046

[23] Mondal S., Nayak L., Rahaman M., Aldalbahi A., Chaki T. K., Khastgir D., Das N. C.: An effective strategy to enhance mechanical, electrical, and electromagnetic shielding effectiveness of chlorinated polyethylene-carbon nanofiber nanocomposites. Composites Part B: Engineering, 109, 155-169 (2017).

https://doi.org/10.1016/j.compositesb.2016.10.049

[24] Zhao P., Wang M., Zhang J.: Influence of chlorosulfonated polyethylene network structure on poly(acrylonitrile-styrene-acrylate)/poly( $\alpha$-methylstyrene-acrylonitrile) blends: Mechanical properties, morphologies, glass transition behavior and heat resistance. Polymer Testing, 57, 175-183 (2017).

https://doi.org/10.1016/j.polymertesting.2016.11.030

[25] Zhang C., Min Y., Bai Y., Gu J., Sun Y.: Fabrication and characterization of chlorinated polyvinyl chloride microporous membranes via thermally induced phase separation process. Journal of Applied Polymer Science, 134, 44346/1-44346/10 (2017).

https://doi.org/10.1002/app.44346

[26] Kolb H. C., Finn M., Sharpless K. B.: Click chemistry: Diverse chemical function from a few good reactions. Angewandte Chemie International Edition, 40, 20042021 (2001).

https://doi.org/10.1002/1521-3773(20010601)40:11<2004 :aid-anie2004>3.3.co;2-x

[27] Tornøe C. W., Christensen C., Meldal M.: Peptidotriazoles on solid phase: [1,2,3]-triazoles by regiospecific copper(I)-catalyzed 1,3-dipolar cycloadditions of terminal alkynes to azides. The Journal of Organic Chemistry, 67, 3057-3064 (2002).

https://doi.org/10.1021/jo011148j

[28] Rostovtsev V. V., Green L. G., Fokin V. V., Sharpless K. B.: A stepwise huisgen cycloaddition process: Copper(I)catalyzed regioselective 'ligation' of azides and terminal alkynes. Angewandte Chemie, 114, 2708-2711 (2002). https://doi.org/10.1002/1521-3773(20020715)41:14<2596::aidanie2596>3.0.co;2-4

[29] Dondoni A.: The emergence of thiol-ene coupling as a click process for materials and bioorganic chemistry. Angewandte Chemie International Edition, 47, 89958997 (2008).

https://doi.org/10.1002/anie.200802516

[30] Dondoni A., Marra A.: Recent applications of thiol-ene coupling as a click process for glycoconjugation. Chemical Society Reviews, 41, 573-586 (2012). https://doi.org/10.1039/c1cs15157f

[31] Uygun M., Tasdelen M. A., Yagci Y.: Influence of type of initiation on thiol-ene 'click' chemistry. Macromolecular Chemistry and Physics, 211, 103-110 (2010). https://doi.org/10.1002/macp.200900442 
[32] Tasdelen M. A.: Diels-Alder 'click' reactions: Recent applications in polymer and material science. Polymer Chemistry, 2, 2133-2145 (2011).

https://doi.org/10.1039/c1py00041a

[33] Tasdelen M. A., Kiskan B., Yagci Y.: Externally stimulated click reactions for macromolecular syntheses. Progress in Polymer Science, 52, 19-78 (2016).

https://doi.org/10.1016/j.progpolymsci.2015.09.003

[34] Yagci Y., Tasdelen M. A.: Mechanistic transformations involving living and controlled/living polymerization methods. Progress in Polymer Science, 31, 1133-1170 (2006).

https://doi.org/10.1016/j.progpolymsci.2006.07.003

[35] Chmielarz P., Fantin M., Park S., Isse A. A., Gennaro A., Magenau A. J., Sobkowiak A., Matyjaszewski K.: Electrochemically mediated atom transfer radical polymerization (eATRP). Progress in Polymer Science, 69, 47-78 (2017).

https://doi.org/10.1016/j.progpolymsci.2017.02.005

[36] Liang L., Astruc D.: The copper (I)-catalyzed alkyneazide cycloaddition (CuAAC) 'click' reaction and its applications. An overview. Coordination Chemistry Reviews, 255, 2933-2945 (2011).

https://doi.org/10.1016/j.ccr.2011.06.028

[37] Hein J. E., Fokin V. V.: Copper-catalyzed azide-alkyne cycloaddition (CuAAC) and beyond: New reactivity of copper(I) acetylides. Chemical Society Reviews, 39, 1302-1315 (2010). https://doi.org/10.1039\%2Fb904091a

[38] Kiskan B., Demiray G., Yagci Y.: Thermally curable polyvinylchloride via click chemistry. Journal of Polymer Science Part A: Polymer Chemistry, 46, 3512-3518 (2008). https://doi.org/10.1002/pola.22685

[39] Pawlak M., Mistlberger G., Bakker E.: In situ surface functionalization of plasticized poly(vinyl chloride) membranes by 'click chemistry'. Journal of Materials Chemistry, 22, 12796-12801 (2012).

https://doi.org/10.1039/c2jm31118f

[40] Demirci G., Tasdelen M. A.: Synthesis and characterization of graft copolymers by photoinduced CuAAC click chemistry. European Polymer Journal, 66, 282289 (2015).

https://doi.org/10.1016/j.eurpolymj.2015.02.029

[41] Akat H., Ozkan M.: Synthesis and characterization of poly(vinylchloride) type macrophotoinitiator comprising side-chain thioxanthone via click chemistry. Express Polymer Letters, 5, 318-326 (2011). https://doi.org/10.3144/expresspolymlett.2011.32

[42] Castelaín M., Martínez G., Marco C., Ellis G., Salavagione H. J.: Effect of click-chemistry approaches for graphene modification on the electrical, thermal, and mechanical properties of polyethylene/graphene nanocomposites. Macromolecules, 46, 8980-8987 (2013). https://doi.org/10.1021/ma401606d
[43] Wu X-M., Wang L-L., Wang Y., Gu J-S., Yu H-Y.: Surface modification of polypropylene macroporous membrane by marrying raft polymerization with click chemistry. Journal of Membrane Science, 421, 60-68 (2012). https://doi.org/10.1016/j.memsci.2012.06.033

[44] Huang H., Niu H., Dong J-Y.: Synthesis of star isotactic polypropylene using click chemistry. Macromolecules, 43, 8331-8335 (2010). https://doi.org/10.1021/ma1019335

[45] Ciftci M., Wang D., Buchmeiser M., Yagci Y.: Modification of polyolefins by click chemistry. Macromolecular Chemistry and Physics, 218, 1700279/1-1700279/5 (2017).

https://doi.org/10.1002/macp.201700279

[46] Amici J., Kahveci M., Allia P., Tiberto P., Yagci Y., Sangermano M.: Polymer grafting onto magnetite nanoparticles by 'click' reaction. Journal of Materials Science, 47, 412-419 (2012).

https://doi.org/10.1007/s10853-011-5814-Z

[47] Tasdelen M. A.: Poly(epsilon-caprolactone)/clay nanocomposites via 'click' chemistry. European Polymer Journal, 47, 937-941 (2011). https://doi.org/10.1016/j.eurpolymj.2011.01.004

[48] Ozlem S., Iskin B., Yilmaz G., Kukut M., Hacaloglu J., Yagci Y.: Synthesis and pyrolysis of ABC type miktoarm star copolymers with polystyrene, poly(lactic acid) and poly(ethylene glycol) arms. European Polymer Journal, 48, 1755-1767 (2012).

https://doi.org/10.1016/j.eurpolymj.2012.07.014

[49] Doganci E., Tasdelen M. A., Yilmaz F.: Synthesis of miktoarm star-shaped polymers with POSS core via a combination of CuAAC click chemistry, ATRP, and ROP techniques. Macromolecular Chemistry and Physics, 216, 1823-1830 (2015).

https://doi.org/10.1002/macp.201500199

[50] Uner A., Doganci E., Tasdelen M. A., Yilmaz F., Gürek A. G.: Synthesis, characterization and surface properties of star-shaped polymeric surfactants with polyhedral oligomeric silsesquioxane core. Polymer International, 66, 1610-1616 (2017).

http://doi.org/10.1002/pi.5420

[51] Schellekens M. A. J., Klumperman B.: Synthesis of polyolefin block and graft copolymers. Journal of Macromolecular Science Part C: Polymer Reviews, C40, 167192 (2000).

https://doi.org/10.1081/mc-100100583

[52] Yaḡci Y., Schnabel W.: Light-induced synthesis of block and graft copolymers. Progress in Polymer Science, 15, 551-601 (1990). https://doi.org/10.1016/0079-6700(90)90006-m

[53] Feng C., Li Y. J., Yang D., Hu J. H., Zhang X. H., Huang X. Y.: Well-defined graft copolymers: From controlled synthesis to multipurpose applications. Chemical Society Reviews, 40, 1282-1295 (2011).

https://doi.org/10.1039/b921358a 
[54] Tinmaz H. B., Arslan I., Tasdelen M. A.: Star polymers by photoinduced copper-catalyzed azide-alkyne cycloaddition click chemistry. Journal of Polymer Science Part A: Polymer Chemistry, 53, 1687-1695 (2015). https://doi.org/10.1002/pola.27612

[55] Durmaz Y. Y., Sangermano M., Yagci Y.: Surface modification of UV-cured epoxy resins by click chemistry. Journal of Polymer Science Part A: Polymer Chemistry, 48, 2862-2868 (2010). https://doi.org/10.1002/pola.24063

[56] Ciftci M., Arslan M., Buchmeiser M., Yagci Y.: Polyethylene-g-polystyrene copolymers by combination of ROMP, $\mathrm{Mn}_{2}(\mathrm{CO})_{10}$-assisted TEMPO substitution and NMRP. Acs Macro Letters, 5, 946-949 (2016). https://doi.org/10.1021/acsmacrolett.6b00460

[57] Ciftci M., Kork S., Xu G. J., Buchmeiser M. R., Yagci Y.: Polyethylene- $g$-poly(cyclohexene oxide) by mechanistic transformation from romp to visible light-induced free radical promoted cationic polymerization. Macromolecules, 48, 1658-1663 (2015). https://doi.org/10.1021/acs.macromol.5b00086

[58] Ciftci M., Norsic S., Boisson C., D'Agosto F., Yagci Y.: Synthesis of block copolymers based on polyethylene by thermally induced controlled radical polymerization using $\mathrm{Mn}_{2}(\mathrm{CO})_{10}$. Macromolecular Chemistry and Physics, 216, 958-963 (2015).

https://doi.org/10.1002/macp.201500016

[59] Durmaz H., Dag A., Erdogan E., Demirel A. L., Hizal G., Tunca U.: Multiarm star block and multiarm star mixed-block copolymers via azide-alkyne click reaction. Journal of Polymer Science Part A: Polymer Chemistry, 48, 99-108 (2010).

https://doi.org/10.1002/pola.23765

[60] Hester J., Banerjee P., Won Y-Y., Akthakul A., Acar M., Mayes A.: ATRP of amphiphilic graft copolymers based on PVDF and their use as membrane additives. Macromolecules, 35, 7652-7661 (2002).

https://doi.org/10.1021/ma0122270

[61] Luo X., Wang G., Pang X., Huang J.: Synthesis of a novel kind of amphiphilic graft copolymer with miktoarm star-shaped side chains. Macromolecules, 41, 2315-2317 (2008).

https://doi.org/10.1021/ma800117d

[62] Li H., Riva R., Jérôme R., Lecomte P.: Combination of ring-opening polymerization and 'click' chemistry for the synthesis of an amphiphilic tadpole-shaped poly( $\varepsilon$ caprolactone) grafted by PEO. Macromolecules, 40, 824-831 (2007).

https://doi.org/10.1021/ma062488f

[63] Yilmaz G., Toiserkani H., Demirkol D. O., Sakarya S., Timur S., Torun L., Yagci Y.: Polysulfone based amphiphilic graft copolymers by click chemistry as bioinert membranes. Materials Science and Engineering: C, 31, 1091-1097 (2011).

https://doi.org/10.1016/j.msec.2011.03.010
[64] Haloi D. J., Naskar K., Singha N. K.: Modification of chlorinated poly(propylene) via atom transfer radical graft copolymerization of 2-ethylhexyl acrylate: A brushlike graft copolymer. Macromolecular Chemistry and Physics, 212, 478-484 (2011).

https://doi.org/10.1002/macp.201000506

[65] Gacal B., Durmaz H., Tasdelen M., Hizal G., Tunca U., Yagci Y., Demirel A.: Anthracene-maleimide-based Diels-Alder 'click chemistry' as a novel route to graft copolymers. Macromolecules, 39, 5330-5336 (2006). https://doi.org/10.1021/ma060690c

[66] Inagaki N., Tasaka S., Imai M.: Hydrophilic surface modification of polypropylene films by $\mathrm{CCl}_{4}$ plasma. Journal of Applied Polymer Science, 48, 1963-1972 (1993). https://doi.org/10.1002/app.1993.070481110

[67] Strobel M., Corn S., Lyons C. S., Korba G. A.: Surface modification of polypropylene with $\mathrm{CF}_{4}, \mathrm{CF}_{3} \mathrm{H}, \mathrm{CF}_{3} \mathrm{Cl}$, and $\mathrm{CF}_{3} \mathrm{Br}$ plasmas. Journal of Polymer Science Part A: Polymer Chemistry, 23, 1125-1135 (1985). https://doi.org/10.1002/pol.1985.170230417

[68] Š́ra M., Trunec D., Stahel P., Buršíková V., Navratil Z., Buršík J.: Surface modification of polyethylene and polypropylene in atmospheric pressure glow discharge. Journal of Physics D: Applied Physics, 38, 621-627 (2005). https://doi.org/10.1088/0022-3727/38/4/015

[69] Kumar S., Bose S., Chatterjee K.: Amine-functionalized multiwall carbon nanotubes impart osteoinductive and bactericidal properties in poly( $\varepsilon$-caprolactone) composites. RSC Advances, 4, 19086-19098 (2014). https://doi.org/10.1039/C4RA00875H

[70] Roohani-Esfahani S-I., Nouri-Khorasani S., Lu Z., Appleyard R., Zreiqat H.: The influence hydroxyapatite nanoparticle shape and size on the properties of biphasic calcium phosphate scaffolds coated with hydroxyapatite-PCL composites. Biomaterials, 31, 5498-5509 (2010). https://doi.org/10.1016/j.biomaterials.2010.03.058

[71] Ishaug-Riley S. L., Okun L. E., Prado G., Applegate M. A., Ratcliffe A.: Human articular chondrocyte adhesion and proliferation on synthetic biodegradable polymer films. Biomaterials, 20, 2245-2256 (1999). https://doi.org/10.1016/S0142-9612(99)00155-6

[72] Zhang M., Li X., Gong Y., Zhao N., Zhang X.: Properties and biocompatibility of chitosan films modified by blending with peg. Biomaterials, 23, 2641-2648 (2002). https://doi.org/10.1016/S0142-9612(01)00403-3 